\title{
LEVANTAMENTO DO ESTADO DA ARTE NOS ESTUDOS DO LAZER: (BRASIL) SÉCULOS XX E XXI - ALGUNS APONTAMENTOS
}

\author{
Elza Peixoto* \\ “(...) se não se domina o já conhecido não é possível de- \\ tectar o não conhecido (...)".
}

(Saviani, 1987, p. 51)

RESUMO: Expõe-se mapeamento do estado da arte nos Estudos do Lazer no Brasil (séculos XX e XXI). Como fontes, recorre-se (1) às obras referidas pelos autores que estudam a produção do conhecimento em recreação e lazer no Brasil; (2) às informaç̧óes prestadas nos currículos cadastrados na Plataforma Lattes (palavras chave recreação, ócio, lazer e tempo livre); (3) ao acervo on line das bibliotecas universitárias, Biblioteca Nacional e Biblioteca do Congresso Nacional. Observa-se a dinâmica da produção do conhecimento, bem como se localiza cronologicamente autores e temáticas privilegiadas. Espera-se que as informações, associadas a estudos históricos radicais e rigorosos do contexto em que esta produção do conhecimento acontece, viabilizem uma melhor compreensão dos processos de produção e veiculação do conhecimento em recreação e lazer no Brasil.

Palavras-chave: Estudos do lazer. Educação. Produção do conhecimento. História.

STATE OF THE ART SURVEY IN LEISURE STUdies (BRAZIL): $\mathrm{XX}^{\mathrm{TH}}$ AND $\mathrm{XXI}^{\text {ST }}$ CENTURIES - SOME NOTES

ABSTRACT: This study presents the state of the art mapping in Leisure Studies in Brazil ( $\mathrm{XX}^{\text {th }}$ and $\mathrm{XXI}^{\mathrm{st}}$ centuries). The following sources of information were used: 1) works mentioned by authors who

Doutoranda em Educação e professora da Universidade Estadual de Londrina (UEL). E-mail: epeixoto@uel.br

Educ. Soc., Campinas, vol. 28, n. 99, p. 561-586, maio/ago. 2007

Disponível em <http://www.cedes.unicamp.br> 
study knowledge production in Recreation and Leisure in Brazil; 2) information given on the curricula registered in Plataforma Lattes (Key words: recreation, idleness, leisure and free time); 3) the online collection of university libraries, National Library, Library of the $\mathrm{Na}$ tional Congress. The dynamics of knowledge production are explored. Authors and privileged themes are chronologically situated. Hopefully, the information associated to radical and strict historical studies of the context in which this knowledge production happens will allow a better understanding of the production processes and knowledge transmission in Recreation and Leisure in Brazil.

Key words: Leisure studies. Education. Knowledge production. History.

\section{Introdução}

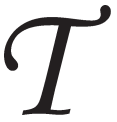

odo e qualquer trabalho acadêmico, independente do tema ou dos objetivos perseguidos, carece do levantamento do conhecimento da produção pré-existente. Chama-se a isso de levantamento do estado da arte - cuja finalidade é reconhecer os avanços e limites na produção do conhecimento a respeito de um determinado tema de estudo. É este conhecimento do estado da arte que permite a identificação de problemáticas significativas para a pesquisa e a ampliação dos conhecimentos em um dado campo. No entanto, qualquer pesquisador que deseje reconhecer o estado da arte dos estudos do lazer vai deparar-se com o problema da dispersão da produção do conhecimento a respeito desta temática. Várias áreas têm dedicado atenção ao estudo do lazer, e a produção daí decorrente espalha-se pelos diversos órgãos e instrumentos de disseminação do conhecimento que atendem às demandas de cada uma destas áreas.

Localizar esta produção dispersa constituía-se em uma importante barreira para amplos levantamentos, principalmente no que toca às publicações em periódicos e eventos, uma vez que demandava a visita às universidades localizadas no Sudeste do país. Os investimentos recentes das bibliotecas públicas na elaboração de catálogos eletrônicos diminuem estas barreiras, abrindo pela primeira vez a possibilidade de um levantamento exaustivo. Destacamos aqui: a disponibilização on- line de informaçōes sobre os acervos das bibliotecas públicas (Congresso Nacional, Biblioteca Nacional e bibliotecas universitárias); a consolidação 
do banco de currículos e grupos de pesquisa do CNPq (Plataforma Lattes); a implementação de bibliotecas eletrônicas de teses e dissertaçōes (portais das bibliotecas universitárias) e periódicos on line (Scielo Brasil, Serviço Cooperativo de Acesso a Documentos - SCAD; Portal de Periódicos CAPES etc.); os esforços, no campo da educação física e esportes, de organização de bancos de dados eletrônicos (PROTEORIA - Instituto de Pesquisa em Educação e Educação Física, NUTESES - Núcleo Brasileiro de Dissertações e Teses em Educação, Educação Física e Educação Especial).

Neste artigo, trazemos os resultados preliminares de um levantamento bibliográfico que objetivou mapear a produção do conhecimento referente aos estudos do lazer no Brasil, tomando como marcos os séculos XX e XXI, resultados estes que nos levam a afirmar (1) a necessidade de organização de um banco de dados específico aos estudos do lazer e (2) a necessidade de revisão crítica desta vasta produção. Como desdobramento destas constatações, com relação ao primeiro ponto, optamos pela organização de um banco de dados de referências bibliográficas a que estamos chamando ARELB (Arquivo Referente aos Estudos do Lazer no Brasil), em fase de preparação para publicação em página na internet. Com relação ao segundo ponto, e sem a pretensão de esgotamento, ensaiamos aqui um esforço preliminar de localização do eixo norteador da preocupação brasileira com a produção do conhecimento e as políticas públicas.

\section{O processo de levantamento}

Em primeiro lugar, desejamos destacar a dificuldade e a complexidade da catalogação destes estudos, tanto por meio do recurso às palavras-chave quanto às áreas de origem/destino destas produçôes, visto a diversidade e imbricamento dos termos que envolvem as discussões, de temáticas subjacentes a estes termos, de formação dos estudiosos e de instrumentos de disseminação da produção. Cita-se, como exemplo, a teia escola/educação/processos pedagógicos/jogo/ brinquedo/brincadeira/lúdico/lazer. Na produção do conhecimento referente aos estudos do lazer, todas as discussōes que abordam o problema da educação para e pelo lazer passam por esta teia de categorias, cujos significados variam conforme os referenciais teóricos e as visões de mundo de que partem os pesquisadores. Desta situação 
Levantamento do estado da arte nos estudos do lazer: (Brasil) séculos XX e XXI...

depreende-se que as categorias não estão fechadas e que estamos muito longe de produzir marcos categoriais dos estudos do lazer claramente delimitados.

$\mathrm{O}$ conjunto destas dificuldades indica a necessidade urgente de análise da produção do conhecimento referente aos estudos do lazer, com vistas ao mapeamento das temáticas que vêm sendo tratadas, dos pressupostos teórico-metodológicos que vêm orientando esta vasta produção bem como da polissemia e paráfrase das categorias-chave definidoras/delimitadoras da temática típica destes estudos do lazer, com vistas à reorganização das palavras-chave que melhor identificam esta produção.

No entanto, precede a esta análise o levantamento e a catalogação da produção do conhecimento. Considerando as dificuldades referidas e o tempo disponível, optamos por realizar o levantamento a partir: (1) das obras referidas pelos autores que produzem conhecimento em estudos do lazer no Brasil; (2) das informaçōes prestadas nos currículos cadastrados na Plataforma Lattes (palavras-chave: recreação, ócio, lazer e tempo livre); (3) dos acervos disponibilizados on line pelas seguintes bibliotecas: Nacional, do Congresso Nacional, do SESC (Unidade Londrina) e das universidades UNICAMP, UFRJ, UFSCAR, UFRGS, USP, UFMG. As consultas às bibliotecas foram realizadas para localizar tanto as obras específicas informadas pelos autores quanto o conjunto de obras de um determinado autor, cuja vida acadêmica não estivesse registrada na Plataforma Lattes. ${ }^{1}$

Nesta primeira etapa da catalogação, foram incluídos apenas dados relativos à produção disseminada por autores brasileiros na forma de (1) artigos completos publicados em periódicos; (2) artigos completos publicados em anais de eventos; (3) capítulos de livros e (4) livros. Em um segundo momento, pretende-se realizar o registro das teses e dissertaçōes, a partir das indicaçōes de Gomes (2004), e o levantamento das referências bibliográficas centrais para cada autor.

Até 15 de maio de 2006, catalogamos um volume de 2.624 trabalhos publicados entre os anos de 1891 e 2006. Este levantamento foi organizado em banco de dados eletrônico que viabilizasse a obtenção de conjuntos de informaçôes - tais como cronologia das publicações, cronologia da produção autor/ano, volume de publicações no século, volume de publicações por década, período de produção 
de cada autor, principais referências da área, principais referências por autor - que pudessem ser, posteriormente, comentadas à luz de estudos históricos conjunturais.

Finalmente, desejamos destacar que no levantamento empreendido junto à base de dados on-line da Biblioteca Nacional, recorrendo às palavras-chave "recreação" e "lazer", isoladamente, localizamos vários materiais bibliográficos datados da segunda metade do século XIX e início do século XX, preocupados com a orientação da recreação e com a disseminação de acervos de jogos, brinquedos, brincadeiras e acervos folclóricos de origem nacional e internacional. Estes outros materiais bibliográficos indicam interesse por orientação da recreação já no século XVIII, em Portugal, e, a considerar o primeiro periódico publicado no Rio de Janeiro, a necessidade de informação voltada para a recreação aparece no Brasil por volta de 1847 , portanto, meados do século XIX. No entanto, estes periódicos não estão sendo considerados em nossas pesquisas, apesar de sua provável contribuiçãa no processo de formação, no senso-comum, de hábitos e valores desejáveis na ocupação do tempo livre, antes mesmo do que Marcassa (2002) vai chamar de "invenção do lazer" no Brasil. Justificamos a exclusão destes materiais argumentando que o movimento de levantamento e catalogação dos estudos do lazer que empreendemos foi orientado pelo interesse em mapear o eixo norteador da produção do conhecimento disseminada pelos que se dedicam aos estudos do lazer como campo do conhecimento, cumprindo o papel de intelectuais que apontam caminhos para as políticas públicas. Reconhecemos que esta situação concretiza-se a partir da década de 30 do século XX, sem descartar a possibilidade de que, em menor escala, estivessem ocorrendo, em períodos anteriores, orientações sobre a fruição do tempo livre, seja por intelectuais portugueses, seja por intelectuais brasileiros.

\section{Apontamentos genéricos e preliminares}

No que toca às áreas do conhecimento, a produção regular catalogada até este instante é oriunda da sociologia (do lazer e do trabalho), do direito do trabalho - referindo-se ao repouso semanal, em feriados e anual -, e também da filosofia, etimologia, história, geografia, administração, economia, arquitetura e urbanismo, matemática, 
Levantamento do estado da arte nos estudos do lazer: (Brasil) séculos XX e XXI...

enfermagem, turismo e hotelaria, educação física (recreação e lazer), antropologia cultural, pedagogia (educação lúdica, educação para e pelo lazer) e psicologia.

No que toca às temáticas e problemáticas, ${ }^{2}$ a produção regular catalogada até este instante contempla: (1) a organização funcional e estética do espaço urbano, com vistas à fruição do tempo livre (Yurgel, 1973); (2) o mapeamento dos interesses/expectativas da população, por segmentos de sexo, idade, profissão, local de trabalho, grau de escolaridade etc. (Goldenstein, 1991; Forjaz, 1988; Bramante, 1990); (3) o mapeamento dos problemas e saídas encontrados por diferentes grupos sociais para a fruição do lazer (Magnani, 1988; Marcellino, 1990); (4) o gerenciamento dos tempos, espaços, equipamentos, pessoal/profissionais e interesses dos participantes no lazer (Bramante, 1997); (5) a descrição das práticas culturais "em moda" e/ou com certa tradição de existência (Bruhns, 2000; Magnani, 1984; Pimentel, 1998); (6) a elaboração/avaliação de políticas públicas voltadas para o lazer nos âmbitos municipal, estadual, nacional e internacional (Marcellino, 1996); (7) a compreensão teórica da relação lazer x trabalho como categoria genérica ou tal como ela ocorre no modo capitalista de produção (Antunes, 1999; Padilha, 2000); (8) a compreensão do movimento de conversão do lazer em mercadoria pelo capital (Falleiros, 1980; Padilha, 2000, 2002, 2005); (9) a história do lazer no Brasil e na história da humanidade (Amaral, 2001; Almeida, 2006; Gomes, 2003; Sussekind, 1950; Marcassa, 2002); (10) o pensamento social sobre o lazer (Oliveira, 1995, 2002; Bruhns, 2002; Marcellino, 2003; Camargo, 1993); (11) as relaçôes funcionais entre lazer e saúde (Bueno, 2004); (12) a superação das doenças do trabalho por meio de processos de atividades desenvolvidas no ambiente de trabalho, geridas pelos departamentos de RH (Marcellino, 1999; Camargo, 1990); (13) uma política de educação para a ocupação/preenchimento do tempo livre no contexto do sistema escolar e fora da escola (Marcellino, 1990; Camargo, 1998; Gaelzer, 1979; Medeiros, 1974; Miranda, 1938); (14) os estudos sobre os jogos no contexto de sua contribuição para o processo pedagógico e na educação (Kischimoto, 1993, 1997; Kamii \& DeVries, 1991; Gouvea, 1934; Pithan \& Silva, 1971); (15) os estudos sobre a educação lúdica/pelo jogo, preconizando-se a educação agradável, atraente, onde a marca da produtividade típica dos processos de trabalho sob orientação do taylorismo/fordismo/toyotismo, 
introduzidos na escola, seja amenizada (Schwartz, 1998; Silva, 1999, 2001; Marcellino, 1990, 2003); (16) a geração de emprego e renda no campo e espaços urbanos litorâneos e interioranos, voltados à estruturação de novas rotas turísticas e à prestação de serviços em turismo e hospitalidade, a partir de áreas geográficas definidas como tendo potencial turístico (Calvente, 2004); (17) os estudos sobre as relações entre lúdico, lazer e educação física (Marcellino, 1999; Bruhns, 1997; Werneck \& Isayama, 2003); (18) os estudos sobre a formação profissional para atuação no lazer (Werneck et al., 2001; Marcellino, 1995); (19) os estudos sobre o lazer no campo da psicologia social (Oliveira, 1994); (20) os estudos sobre a produção do conhecimento em recreação e lazer - referenciais teóricos e metodológicos norteadores (Sá, 2003; Marcellino, 1986; Valente, 1997; Gomes, 2004; Guimarães, 2001); (21) produção do conhecimento e metodologias da pesquisa em lazer (Magnane, 2000).

No que toca à polissemia e paráfrase, observa-se que a produção do conhecimento recorre aos termos "tempo livre", "recreação", "lazer", "ócio", "lúdico" e "jogo" para referir-se a um conjunto de açóes cujos significados envolvem os seguintes eixos: (1) concessão de tempo livre legalmente regulamentado ao trabalhador, com a garantia de aproveitamento "adequado" de suas horas de lazer, o que exige do poder público a implementação de políticas de gestão do tempo livre, a fim de evitar colocar "em perigo a obra social e cultural que se desejou iniciar com a regulamentação legal da duração do trabalho" (Sussekind, 1950); (2) reformulação dos processos tradicionais de ensino, sob influência do projeto escolanovista de "educar o povo e transformar a sociedade", instaurando uma cultura "capaz de assegurar a unidade da nação" (Gomes, 2003, p. 162), baseada em projetos elaborados por uma elite de intelectuais "aptos para representar os interesses das elites" direcionados à educação da população pobre e analfabeta - neste contexto, a recreação aparece como um projeto de aprimoramento cultural do povo, compondo o processo de conformação da classe trabalhadora ao projeto de sociedade da elite burguesa no Brasil (Braga, 2005; Gomes, 2003; Marcassa, 2002).

$\mathrm{Na}$ diversidade que caracteriza os estudos do lazer, faz-se necessário localizar: (1) o eixo norteador/justificador desta produção; (2) as características deste eixo ao longo do tempo, com possibilidade de configuração de ciclos de produção do conhecimento. 
No que toca ao eixo norteador da produção do conhecimento, reafirmamos a tese de que é a ocupação do tempo livre ou dos "usos do tempo livre" que absorve boa parte dos estudos do lazer no Brasil (Peixoto, 1996; Sant'Anna, 1994). O acompanhamento progressivo desta produção permite observar a preocupação com a distinção entre lazer e ócio, com a indicação de atividades adequadas para o preenchimento do tempo livre e com divulgação de estudos que demonstram o modo como a população organiza a vida cotidiana e usufrui o lazer.

A produção do conhecimento referente aos estudos do lazer no Brasil coaduna-se com o projeto de conformação da classe operária ao projeto de desenvolvimento econômico burguês para o país. Os estudos que fazem a crítica ideológica destas produçóes são raros e, em muitos casos, carentes de veemência.

Apontamentos e indicadores para a estruturação de ciclos de conhecimento

Considerando-se a cronologia e o volume dos trabalhos levantados até este instante, é possível observar um primeiro ciclo de publicações brasileiras regulares acontecendo a partir do ano de 1934. Este primeiro ciclo, que vai de meados da década de 1930 até meados da de 1960, é marcado pela (1) produção de justificativas para a implementação de políticas de ocupação do tempo livre das crianças e de educação para o tempo livre; (2) organização e disseminação de acervos de jogos, brinquedos e brincadeiras, entre outras práticas sociais consideradas adequadas para a ocupação do tempo livre das crianças no interior e fora da escola; (3) produção de justificativas científicas, relacionadas à produtividade no trabalho, para a redução regulamentada da jornada de trabalho e para o planejamento e implementação de políticas públicas voltadas a uma adequada ocupação do tempo livre do trabalhador

Observa-se que a produção e disseminação do conhecimento, na forma de acervos de jogos, brinquedos, brincadeiras, práticas folclóricas e atividades manuais, estão voltadas (1) à dinamização do ensino escolar, (2) à educação moral das crianças, (3) a reflexões que subsidiem a geração de espaços institucionais para a ocupação do tempo livre; (4) à educação para a ocupação do tempo livre; (5) ao desenvolvimento 
físico de crianças, jovens e adultos. Este esforço de produção de acervo e de orientação sobre seus valores para a educação das crianças e jovens vai se manter nos anos seguintes, culminando na estruturação de manuais de recreação, com forte conotação moralista. Destaca-se também que nas décadas de 1920, 1930 e 1940 são desenvolvidas experiências de políticas públicas destinadas à ocupação do tempo livre de crianças, jovens e adultos (Marcassa, 2002; Gomes, 2003), que vão se apoiar sobre esta produção. Neste período, observa-se (1) um intenso debate sobre a necessidade de lazer para os trabalhadores (Sodré, 1938; Sussekind, 1946, 1948; Braga, 2005); (2) um trânsito intenso dos intelectuais entre o Brasil e o exterior - conforme informam os depoimentos de Medeiros (2003) e Sussekind (2004) e os estudos de Gomes (2003) sobre Frederico Guilherme Galezer - evidenciando o esforço de alinhamento com a política mundial de ocupação do tempo livre do trabalhador (Sussekind, 1950).

Na década de 1930, encontramos os trabalhos de Ruth Gouvêa (1934), Frederico Guilherme Gaelzer (1935) e Nicanor Miranda (1938). Na década de 1940, mantém-se a produção de trabalhos voltados à oferta de acervo de jogos, brinquedos e brincadeiras, surgindo também os primeiros trabalhos no contexto trabalholtempo livrelocupação do tempo livre do trabalhador, produzidos no campo do direito por Sussekind $(1946 ; 1948 ; 1949)$. Na década de 1950 , observa-se um incremento na produção, que chega a 20 trabalhos publicados, atingindo-se o dobro da década anterior. Destacam-se neste período: os trabalhos de Gaelzer sobre a recreação pública (1951 e 1952); os trabalhos de Sussekind referentes a estudos históricos e jurídicos sobre a Duração do trabalho e repousos remunerados (1950) e o Manual de recreação: orientação dos lazeres do trabalhador (1952); os estudos sobre Recreação infantil (1952), de Elisa Velloso, Rio de Janeiro; os trabalhos de Dante Costa $(1947,1953)$ relacionados a parques infantis, infância e recreação; o trabalho de Gouvêa (1955) sobre jogos infantis, publicado pelo INEP; os trabalhos de Ethel Bauzer Medeiros relativos ao Plano de um manual de recreação elementar (1954), sobre a Importancia e a necessidade da recreação (1957), sobre Recreação e parques públicos (1958) e alguns catálogos contendo acervos de jogos (1959). Inezil Penna Marinho publica Curso de fundamentação e técnicas da recreação (1955), Os jogos - principais teorias (1956) e Educação Física, recreação e jogos (1957). N. Pithan e Silva publica seu 
Levantamento do estado da arte nos estudos do lazer: (Brasil) séculos XX e XXI...

Manual de recreação (1959) e o baiano Acácio Ferreira, Lazer operário: um estudo de organização social das cidades (1959).

$\mathrm{Na}$ década de 1960, encontramos 21 trabalhos publicados, 13 destes sendo de Medeiros (1960, 1961, 1964), relativos a reediçôes de manuais de acervos de jogos, a elementos para o planejamento da recreação pública municipal, ao papel do educador no planejamento da recreação pública e a estudos sobre infância e literatura. Temos também o trabalho de Lelia Iacovo publicado pelo SESI, cujo título é Ensaios de recreação (1960); o manual clássico de Gouvêa intitulado Recreação (1963); a terceira edição do Manual de educação física, jogos e recreação (1966), de Teixeira \& Mazzei; o trabalho de J. C. de Oliveira Torres, Lazer e cultura (1968); e o clássico de Maria Junqueira Schmidt, Educar pela recreação (1968).

Vale destacar que, nas décadas de 1950 e 1960, são traduzidos para o português e publicados no Brasil alguns autores de expressão internacional: Bertrand Russel (O elogio do lazer, 1957); Thorstein Veblen (A teoria da classe ociosa, 1965); Herbert Marcuse (A ideologia da sociedade industrial, 1967; Eros e civilização, 1968); e Wright Mills (A nova classe média, 1969). Estas traduçôes são indicativas da existência de interesse crescente dos intelectuais pela temática e da relevância social que a mesma vai adquirindo. Destaca-se, ainda, que acontece em 1963 o Curso de Especialização em Recreação Operária, oferecido pelo Serviço de Recreação Operária da Comissão do Imposto Sindical (sROCIS, Brasil). ${ }^{3}$ A World Leisure and Recreation Association (WRLA) é fundada em 1952.

Podemos dizer que os marcos do segundo ciclo da produção do conhecimento sobre os estudos do lazer no Brasil são os clássicos Ócius versus trabalho (Ferreira da Silva, 1964) e As dimensóes do lazer (Requixa, 1969). Neste ciclo, o aprimoramento teórico conceitual e a ampliação dos estudos empíricos sobre o lazer priorizam o conhecimento dos "usos do tempo livre", configurando-se como "planos, pesquisas e programas incentivadores de novas formas de praticar o lúdico, de aproveitar o tempo livre e nele ter prazer" (Sant'Anna, 1994, p. 3839). Este segundo ciclo vai ocorrer a partir da segunda metade da década de 1960, sendo impulsionado em toda a década de 1970 pelo CELAR $^{4}$ (Porto Alegre) e pelo CELAZER/SESC, de onde saem os autores que vão deflagrar a produção deste segundo ciclo e formar os quadros que 
serão responsáveis pelos terceiro e quarto ciclos da produção do conhecimento brasileira. Observa-se, ainda, que além da produção oriunda do SESC e da PUC-RS, intelectuais de projeção nacional pronunciam-se acerca do problema (Freire, 1970; 1971). É um ciclo marcado por intensos debates quanto aos usos do tempo livre, quanto à distinção entre lazer e ócio e à relação entre estes e o trabalho, com supervalorização do primeiro termo (Reale, 1980; Marcellino, 1983; Sant'Anna, 1994; Camargo, 2003), dando-se continuidade ao projeto de conformação da classe operária no Brasil.

O SESC, por sua vez, além da atuação na prestação de serviços em lazer, também estruturou o Centro de Estudos do Lazer e da Recreação (CELAZER), atuando como editor na década de 1970, especialmente a partir de 1974. Publicou ainda o Boletim de Intercâmbio, Cadernos de Lazer e a série Lazer, da Biblioteca Científica SESC, entre outras obras dos intelectuais a ele ligados. Entre os marcos deste segundo ciclo, encontramos o I Encontro Nacional sobre Lazer Cultura ${ }^{5}$ (Recreação e Educação Física), que ocorreu no Rio de Janeiro, de 24 a 29 de agosto de 1975, com trabalhos disseminados em Anais. O evento foi realizado pelo SESC e patrocinado pelo Ministério do Trabalho. Em 1976, o SESC promoveu o I Encontro Nacional de Recreação, também realizado pelo Departamento Nacional da entidade no Rio de Janeiro, reunindo as experiências de seus departamentos regionais. ${ }^{6}$ Ocorreu também o II Seminário Mundial de Lazer (abril, 1976), durante o qual se elaborou a "Carta do Lazer".

$\mathrm{Na}$ década de 1970 , temos a primeira explosão na produção do conhecimento referente aos estudos do lazer, com 87 publicações. Entre os trabalhos publicados nesta fase, encontramos, de Gilberto Freyre, Tempo, ócio e arte: reflexões de um latino-americano em face do avanço da automação (1970) e Um assunto atualíssimo: os tempos sociais (1971). Francisco de Macedo Riopardense publica $O$ uso do tempo e o equipamento urbano de recreação (1970). Ethel Bauzer Medeiros publica O lazer no planejamento urbano (1971); Atividades lúdicas populares (1972); O educador e a atividade criadora (1974); e os artigos Valor da recreação nos países em desenvolvimento (1974); O lazer no mundo atual (1974). Marlene Yurgel (1972, 1973, 1974) publica uma série de trabalhos no campo da arquitetura, urbanismo e lazer, e Roberto Burle Marx publica Áreas verdes e lazer (1974). 
Levantamento do estado da arte nos estudos do lazer: (Brasil) séculos XX e XXI...

Lamartine Pereira da Costa publica Esporte para todos (1975). Lenea Gaelzer publica quatro trabalhos ligados à recreação e, entre estes, o clássico Lazer: benção ou maldição? (1979), prefaciado por Inezil Penna Marinho que, neste ano, publica Raizes etimológica, histórica e jurídica do lazer (1979). Paulo Nunes de Almeida publica Dinâmica lúdica, técnicas e jogos pedagógicos (1974) e A explosão recreativa dos jogos (1977). Maria Heloísa Fénelon Costa se pergunta: Há lazer entre os carajás? (1975). Emile Derlon Linson se pergunta: O lazer é um problema nos paises em desenvolvimento? (1975). Renato Requixa escreve: Lazer e ação comunitária (1973); O lazer e a civilização urbana (1974); As dimensões do lazer (1976); O lazer na grande cidade e os espaços urbanizados (1977); O lazer no Brasil (1977). Luiz Otávio de Lima Camargo inicia suas publicações com Lazer e preservação do patrimônio cultural (1978) e com Recreação pública (1979). Cecília Torreão Stramandinoli publica Aspectos psicológicos do lazer (1971) e José Inácio Parente, Lazer e psicologia preventiva (1977). José Otão escreve A educação permanente e o lazer (1973) e Alípio Pires Castello Branco publica Educação, lazer e vida urbana (1973). Manoel José Gomes Tubino publica Colônia de férias (1973).

O terceiro ciclo da produção do conhecimento terá como marcos a abordagem dos estudos do lazer como temática dos programas de pós-graduação e os eventos regulares realizados especialmente pela Educação Física durante as décadas de 1980 e 1990. Nesta fase, ocorrem intensos debates que vão expor as ideologias nas quais a problemática do lazer está envolta, disseminando-se trabalhos de crítica à produção do conhecimento e à matriz ideológica que a caracteriza. Em 1980, ocorre a III Semana de Estudos Turísticos em Campinas. Em 1989 ocorre, em Brasília, o I Encontro Nacional de Profissionais de Recreação e Lazer, que passará a ocorrer anualmente. Em 1990, o Programa de Pós-graduação da Faculdade de Educação Física da UNICAMP mantém um Departamento de Estudos do Lazer (DEL), ofertando em 1991 a primeira turma do Curso de Especialização em Lazer. Em 1993, são iniciados os Encontros Nacionais de História do Esporte, Lazer e Educação Física (anuais); em 1997, o Congresso Brasileiro de Ciências do Esporte (bianual) inicia a inscrição para a exposição de trabalhos em grupos de trabalho temáticos (Espaço do CBCE, 1996, p. 296-298); em 2000, o CELAR/ufmG inicia os Seminários Lazer em Debate (anuais) e o DEL/FEF/UNICAMP inicia os seus Ciclos 
de Debates Lazer e Motricidade (1999, 2000, 2001). Destaca-se, ainda, que em 1998 publica-se o primeiro número do periódico Licere (Gomes e Melo, 2003). Este conjunto de açôes no campo da produção do conhecimento e da organização de sua disseminação, juntamente com a política de capacitação e estímulo à produção do conhecimento, implementada pela Coordenação de Aperfeiçoamento de Pessoal de Nível Superior (CAPES), preparam as condiçôes para um fluxo crescente de publicaçóes, de modo que, na década de 1980, temos um total de 113 publicações; na década de 1990, temos um total de 582 trabalhos publicados; e nestes seis primeiros anos desta primeira década do século XXI a produção sobe para 1.754 trabalhos. Se quisermos ver isto em termos de média, temos 11,3 trabalhos/ano na década de 1980, 58,2 trabalhos/ano na década de 1990 e 292 trabalhos/ano nesta primeira década do século XXI.

$\mathrm{Na}$ década de 1980, encontramos a produção inicial da geração de autores que vão ser responsáveis pela formação dos profissionais que atuarão no ensino superior nas duas décadas seguintes. Destacamos Nelson Carvalho Marcellino; Kátia Brandão Kavalcanti; Paulo de Salles Oliveira; Luiz G. G. Trigo; Newton Cunha; Maria Isabel de Souza Lopes; Maria Isabel Leme Faleiros; Dante Silvestre Neto; Lílian A. B. do Valle; Yara Maria Kuster; Sarah Bacal; Maria Cecília Spina Forjaz; Liz Cintra Rolim; Marília Gomes dos Reis Ansarah. Ao mesmo tempo, Ethel Bauzer Medeiros, Renato Requixa, Luiz Otávio de Lima Camargo e Lenea Gaelzer mantêm suas produções. Todos os textos deste período são conhecidos pela maior parte das novas geraçóes de estudiosos do lazer, mas destacam-se dois trabalhos que nos chamam especial atenção: a apresentação de Francisco Foot-Hardman, "Trabalho e lazer no movimento operário" (1980), feita para a primeira edição brasileira de $O$ direito à preguiça (Paul Lafargue, 1880), e o texto de Miguel Reale, $O$ direito de não trabalhar (1980), a nosso ver, textos pouco explorados pelos estudiosos da área.

Na década de 1990, somam-se a estas publicações os trabalhos de Antonio Carlos Bramante, Márcia Ferreira Chaves, Márcia de Franceschi Neto, Ademir Gebara, Heloisa Turini Bruhns, Luiz Wilson Pina, Denise Santana, Ricardo Antunes, Tereza L. França, Victor Andrade de Melo, Giuliano Gomes de Assis Pimentel, Valquiria Padilha, Christianne Luce Gomes, Hélder Ferreira Isayama e uma série de outros autores ${ }^{8}$ que vão sendo formados por programas de pós-graduação dirigidos à 
Levantamento do estado da arte nos estudos do lazer: (Brasil) séculos XX e XXI...

formação de profissionais para atuação no campo da recreação e lazer (na formação profissional, produção do conhecimento ou políticas públicas), ou que vão desenvolver suas dissertaçóes e teses - em diversificados programas de pós-graduação - no contexto dos estudos do lazer.

$\mathrm{O}$ quarto ciclo da produçáo do conhecimento inicia-se no final da década de 1990, quando se multiplicam os grupos de estudos e pesquisas fundados pelos pesquisadores formados nas décadas de 1980 e 1990, impulsionados pelas diretrizes do Conselho Nacional de Pesquisa (CNPq) e da Coordenação de Aperfeiçoamento de Pessoal de Nível Superior (CAPES) para a pós-graduação e a produção do conhecimento. Em 10 de abril de 2006, em busca textual no Diretório dos Grupos de Pesquisa no Brasil, encontramos cadastrados no CNPq 70 grupos com linhas de pesquisa relacionadas ao lazer, com datas de fundação variando entre 1995 e 2005, o que nos coloca diante de dez anos de ação dos grupos de pesquisa, contribuindo com a qualificação de pesquisadores desde a graduação até o doutoramento. A quarta geração de pesquisadores que estudam o lazer no Brasil origina-se destes grupos de estudos e pesquisas, direcionando-se para a produção do conhecimento e para a atuação no ensino superior. As temáticas multiplicam-se, ao mesmo tempo em que se multiplicam os pesquisadores interessados na área.

Este período vai estar marcado pela produção do conhecimento extremamente burocratizada e pela preocupação com a produtividade medida em quantidade de trabalhos publicados. Predomina a produção do conhecimento direcionada aos interesses de mercado (principalmente o editorial), no que toca à formação profissional e aos interesses e conteúdos culturais. No seio desta preocupação, e em contradição com este movimento, avolumam-se os trabalhos que fazem a revisão crítica do lazer como prática social, retomando o debate silenciado na década de 1980 (Padilha, 2000, 2006; Mascarenhas, 2005). Destacam-se os esforços em direção à compreensão da história da produção do conhecimento (C.L. Gomes, 2003; C.M. Gomes, 2004) e da história da formação profissional em recreação e lazer (Costa e Silva; Vago, 2005). A seguir, o gráfico do fluxo da produção do conhecimento referente aos estudos do lazer no Brasil demonstra que, a partir de 1990, torna-se impraticável listar os autores que vêm surgindo, visto a imensa quantidade de estudiosos interessados nesta 
temática, e disseminando com frequiência suas produções, o que reforça a necessidade de organização desta imensa produção em um banco de dados que facilite o acesso, preparando as bases para a sua revisão crítica.

\section{Gráfico 1}

Fluxo da produção do conhecimento referente aos estudos do lazer no Brasil

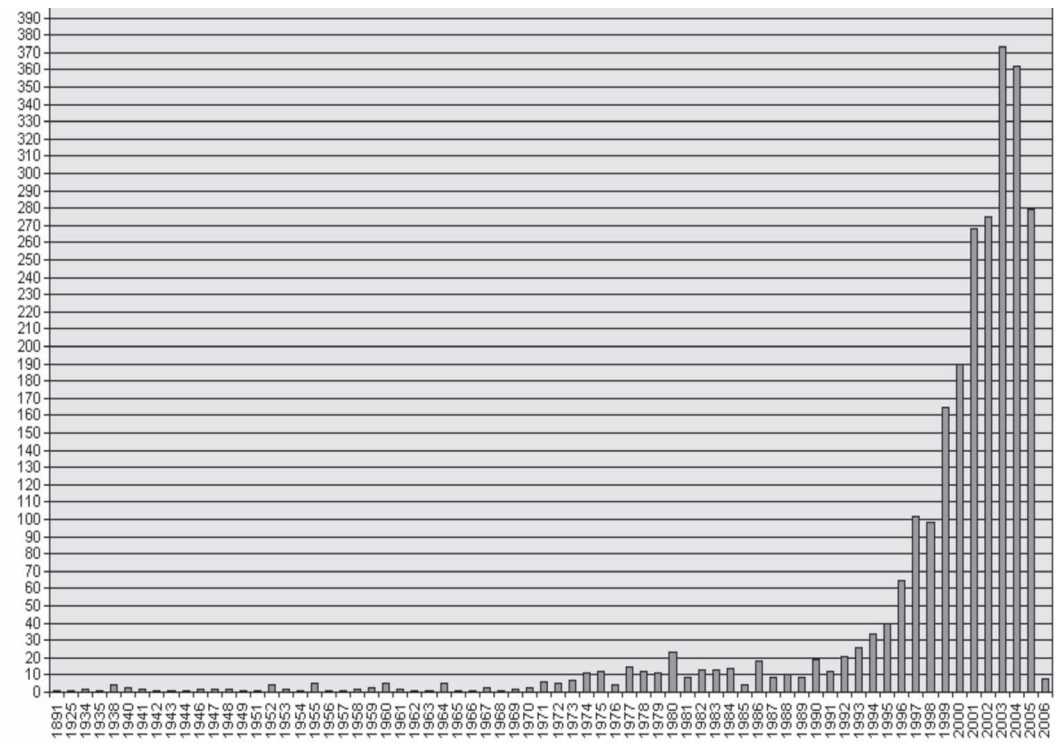

\section{Considerações finais}

Estes apontamentos preliminares vêm se somar aos estudos que estão buscando compreender a dinâmica da produção do conhecimento em recreação e lazer no Brasil, nos séculos XX e XXI. Nesta direção, teço algumas considerações com relação ao que entendo como entraves a uma adequada percepção desta dinâmica. Em primeiro lugar, apoiada nas informações recolhidas neste levantamento, reforço a necessidade de revisão das afirmações que apontam a origem desta produção do conhecimento na segunda metade do século Xx. A preocupação com a estruturação de políticas de formação de hábitos de ocupação do tempo livre para crianças, 
jovens e trabalhadores origina-se em nível internacional, com repercussões no Brasil bem antes deste período, nas décadas de 1920 e 1930, o que leva a um conjunto de publicações centradas na discussão de políticas públicas e visando à construção de proposições com clara indicação de organização de espaços e atividades, e com justificativa teóricometodológica extremamente consistente.

A colocação da década de 1970 como marco, a meu ver, ocorre, em primeiro lugar, em virtude da insistência na distinção conceitual recreação/lazer (entre outras categorias); em segundo lugar, decorre da evidente visibilidade obtida pelo conjunto de açôes implementadas pelo Serviço Social do Comércio (por meio do CELAZER) e pela PUC-RS (por meio do CELAR). Estudos históricos da produção do conhecimento, baseados na distinção entre recreação/lazer, incorrem no risco de construir visões limitadas acerca da dinâmica histórica que produz os estudos do lazer no Brasil.

Apenas observando a dinâmica histórica da produção do conhecimento, de modo associado à conjuntura política e econômica, podemos compreender um conjunto de políticas públicas implementadas nas décadas de 1930 e 1940, que recorrem à recreação/lazer com finalidade social claramente especificada nas produções: a concessão de tempo livre condicionada a uma política de ocupação que trouxesse vantagens à burguesia, no processo de organização da produção industrializada no Brasil. Refirome àquilo que Braga (2005) vai nomear como política de conformação da classe trabalhadora, empreendida na primeira metade do século XX.

Encerro recordando que a discussão detida das características da produção em cada período caracteriza os levantamentos do estado da arte. Obviamente, não esgotei este objetivo. O esforço coletivo dos estudiosos da área pode permitir a análise minuciosa desta produção, apontando os avanços e limites das diferentes contribuições a cada ciclo. Demos aqui, nesta direção, apenas um primeiro passo.

Recebido em junho de 2006 e aprovado em março de 2007.

\section{Notas}

1. No caso de Ethel Bauzer Medeiros; Inezil Penna Marinho; Lenea Gaelzer; Frederico Guilherme Gaelzer; Acácio Ferreira; Arnaldo Sussekind; Miguel Reale; Gilberto Freire; Marlene Guerra; Ruth Gouvêa; Maria Junqueira Schmidt, Nicanor Miranda. 
2. Por uma questão de espaço, optamos por listar aqui as temáticas mapeadas até este instante, seguidas de alguns autores que a elas estão se dedicando ou que organizaram coletâneas que reúnem estas produções.

3. Lamartine Pereira da Costa participa deste Curso de Especialização. Fonte: Currículo do autor. Plataforma Lattes. Acesso em 30 de janeiro 2006.

4. O CELAR - Centro de Estudos do Lazer (1973-1978) - foi criado em um processo de ampliação das políticas públicas voltadas para o lazer e implementadas pela Administração Pública de Porto Alegre, por meio da Secretaria Municipal de Educação e Cultura para, entre outras atribuiçôes, administrar os "Centros de Comunidade" através de um contrato de prestação de serviços entre a prefeitura de Porto Alegre e a PUC. A intenção era gerar um "terceiro setor" que viabilizasse a operacionalização dos Centros de Comunidade sem os entraves oriundos da estrutura burocrática das prefeituras. Tratava-se de um projeto integrado de pesquisa, formação e prática profissional. As ações do CELAR começaram com um Encontro Estadual sobre Lazer (1974) e com o Curso de Especialização em Lazer (1975). Atuaram no Celar Zillah Totta, Liz Cintra Rolim, Lenea Gaelzer (convidada), Luiz Oswaldo Leite, Lúcia Castilho e Wilmar Figueiredo de Souza (2002).

5. Participaram deste evento Zilah Totta, Lamartine Pereira da Costa, Lenea Gaelzer, Jofre Dumazedier, Renato Requixa e Ruth Gouvêa.

6. Departamentos Regionais do Paraná, Minas Gerais, Pará, Capital Federal, Ceará, Amazonas, São Paulo, Santa Catarina, Sergipe, Piauí, Paraíba e Mato Grosso e Acervos do Rio de Janeiro e da Guanabara. Fonte: Encontro Nacional de Recreação (Experiências dos Departamentos Regionais.), 1, Rio de Janeiro, 1977, Rio de Janeiro. Anais... Rio de Janeiro, SESC, 1976.

7. No СвСE, realizado em 1997 em Goiânia, são implantados 12 Grupos de Trabalhos Temáticos, entre estes o GTT6 - Educação Física/Esporte e Recreação/Lazer.

8. Em virtude do espaço disponível, estamos impossibilitados de fazer referência às obras de todos os autores citados. Para conhecimento da produção dos autores que citamos e de outros autores da área, sugerimos (1) busca de currículos por palavras-chave (recreação, lazer, tempo livre, lúdico) e (2) busca de currículos por nome completo do autor.

\section{Referências bibliográficas}

\section{ALBUQUERQUE, I. Jogos e recreaçôes matemáticas. Rio de Janeiro: Getúlio Costa, 1942.}

ALMEIDA, M.A.B.; GUTIERREZ, G.L. O governo Vargas e o desenvolvimento do lazer no Brasil. Efdeportes.com Revista Digital, Buenos Aires, v. 10, n. 92, jan. 2006. Disponível em: <http:// www.efdeportes.com.>. Acesso em: 23 jan. 2006.

ALMEIDA, M.A.B.; GUTIERREZ, G.L. Desenvolvimentismo e lazer. Efdeportes.com Revista Digital, Buenos Aires, v. 10, n. 87, ago. 
Levantamento do estado da arte nos estudos do lazer: (Brasil) séculos Xx e XXI...

2005. Disponível em: <http://www.efdeportes.com.>. Acesso em: 25 ago. 2005.

ALMEIDA, P.N. Dinâmica lúdica, técnicas e jogos pedagógicos. São Paulo: Loyola, 1974.

ALMEIDA, P.N. A explosão recreativa dos jogos. São Paulo: Estrutura, 1977.

AMARAL, S.C.F. Espaços e vivências públicas de lazer em Porto Alegre: da consolidação da ordem burguesa à busca da modernidade urbana. Revista Brasileira de Ciências do Esporte, Goiânia, v. 23, n. 1, p. 109-121, set. 2001.

ANTUNES, R.L.C. Os sentidos do trabalho: ensaio sobre a afirmação e a negação do trabalho. São Paulo: Boitempo, 1999.

BRAGA, L.S. Uma civilização sem alma?: educação e revolução passiva. 2005. 191f. Dissertação (Mestrado) - Faculdade de Educação, Universidade Estadual de Campinas, Campinas.

BRAMANTE, A.C. Recreação para o trabalhador: a necessidade de formulação de um diagnóstico de interesses. In: QuinTAS, G. (Org.). Esporte e lazer na empresa. Brasília, DF: MEC/SEED, 1990.

BRAMANTE, A.C. Qualidade no gerenciamento do lazer. In: Bruhns, H. T. (Org.). Introdução aos estudos do lazer. Campinas: Autores Associados, 1997. p. 123-153.

BUENO, S.M.V.; CAMARGO, R.A.A. Lazer, trabalho e promoção da saúde mental para os trabalhadores de hospital Escola Anna Nery. Revista de Enfermagem, Rio de Janeiro, v. 8, n. 1, p. 71-80, 2004 .

BURLE MARX, R. Áreas verdes e lazer. In: SEMINÁRIO DO LAZER. Anais... Curitiba: SESC, 1974. p. 10-16.

CASTELLO BRANCO, A.P. Educação, lazer e vida urbana. Revista de Cultura Vozes, Petrópolis, v. 67, n. 3, p. 217-228, abr. 1973.

CALVENTE, M.D.C.M.H.; BORBA, M.A.J.G. Geografia, ócio, lazer, turismo e ensino. In: Asari, A.A.; Antonello, I.T.; Tsukamato, 
R.Y. (Org.). Múltiplas geografias: ensino, pesquisa e reflexão. Londrina: EDUEL, 2004. p. 225-244.

CAMARGO, L.O.L. A pesquisa em lazer na década de 70. In: SEMINÁRIO “O LAZER EM DEBATE”, 4., 2003, Belo Horizonte. Anais... Belo Horizonte: UfMG, 2003.

CAMARGO, L.O.L. Lazer e preservação do patrimônio cultural. Revista Arquitetura, São Paulo, n. 19, p. 23-28, 1978.

CAMARGO, L.O. L. Recreação pública. Cadernos de Lazer, São Paulo, n. 4, p. 29-36, 1979.

CAMARGO, L.O. L. Educação para o lazer. São Paulo: Moderna, 1998.

CONSELHO NACIONAL DE DESENVOLVIMENTO CIENTÍFICO E TECNOLOGICO. Plataforma Lattes. Disponível em: <http://lattes.cnpq.br/index.htm>. Acesso em: 22 jan. 2006.

COSTA E SILVA, M.G.; VAGO, T.M. Uma história da recreação (1952-1970): constituição inicial da disciplina no curso de educação física da escola de educação física de Minas Gerais. In: SEMINÁRIO “O LAZER EM DEBATE”, 4., 2003, Belo Horizonte. Anais... Belo Horizonte: UFMG, 2003.

COSTA, D. A infância e a recreação. Rio de Janeiro: Imprensa Nacional, 1947.

COSTA, D. Parques infantis para cidades do interior. 5. ed. Rio de Janeiro: Imprensa Nacional, 1953.

COSTA, M.H.F. Há lazer entre os Carajás? Arte \& Educação, Rio de Janeiro, v. 17, n. 4, p. 4-5, mar. 1975.

COSTA, L.P. O esporte para todos. In: ENCONTRO NACIONAL SOBRE LAZER, 1., 1975, Rio de Janeiro. Anais... Rio de Janeiro: SESC, 1975.

DIAS NETO, R. Lissére... Litchére... Likére. Afinal, o que é lícito? Licere, Belo Horizonte, v. 2, n. 1, 1999.

ESPAÇO DO CBCE: informes do colégio brasileiro de ciências do esporte. Motrivivência, Florianópolis, v. 8, n. 9, p. 297-298, dez. 1996. 
Levantamento do estado da arte nos estudos do lazer: (Brasil) séculos XX e XXI...

FALEIROS, M.I.L. Repensando o lazer. Perspectiva, São Paulo, n. 3, p. 51-65, 1980.

FERREIRA DA SILVA, V. Ócio versus trabalho. In: FerreIra DA SiLVA, V. Obras completas. São Paulo: Instituto Brasileiro de Filosofia, 1964. 2v., p. 449-451.

FORJAZ, M.C.S. Lazer e consumo cultural das elites. Revista Brasileira de Ciências Sociais, São Paulo, v. 3, n. 6, p. 99-113, fev. 1988.

FREYRE, G. Um assunto atualíssimo: os tempos sociais (1971). Disponível em: <http://prossiga.bvgf.fgf.org.br/portugues/index.html>. Acesso em: 2 fev. 2006.

FREYRE, G. Tempo, ócio e arte: reflexões de um latino-americano em face do avanço da automação (1970). Biblioteca Virtual Gilberto Freire. Disponível em: <http://prossiga.bvgf.fgf.org.br/portugues/ index.html>. Acesso em: 2 fev. 2006

FUNDAÇÃO BIBLIOTECA NACIONAL. Catálogos on line. Disponível em: <http://catalogos.bn.br/>. Acesso em: 21 fev. 2006.

GAELZER, F.G. Bailado: folclore internacional. Porto Alegre: Globo, 1935 .

GAELZER, L. Recreação pública em Porto Alegre: evolução histórica. Porto Alegre: UfRGS, 1975.

GAELZER, L. As atividades de grupo na recreação: formação de clubes. Porto Alegre: EMMA, 1978

GAELZER, L. O recreio na escola de primeiro grau. 2. ed. Porto Alegre: UFRGS, 1979

GAELZER, L. Lazer: benção ou maldição? Porto Alegre: Sulina; UFRGS, 1979.

GANDRA, E.A.; SILVA, A.J.; NASCIMENTO, M.I.M. A orientação político-educacional no populismo e a evolução da estratégia liberal para conter a mobilização operária. Revista HISTEDBR On-line, Campinas, n. 19, p. 117-133, set. 2005.

GOLDESTEIN, G.T. Lazer operário e consumo cultural na São Paulo dos anos oitenta. Revista de Administração de Empresas, São Paulo, v. 31, n. 3, p. 13-35, jul./set. 1991. 
GOMES, C.L. Lazer e trabalho no contexto urbano: reflexôes sobre os "clubes de menores operários" (1937-1947). In: Müller, A.C.L. Lazer e trabalho: um único ou múltiplos olhares? Santa Cruz do Sul: EDUNISC, 2003.

GOMES, C.L.; MELO, V.A. Lazer no Brasil: trajetória de estudos, possibilidades de pesquisa. Movimento, Porto Alegre, v. 9, n. 1, p. 2344, jan./abr. 2003.

GOMES, C.L. Significados da recreação e lazer no Brasil: reflexões a partir da análise de experiências institucionais (1926-1964). 2003. 322f. Tese (Doutorado) - Faculdade de Educação, Universidade Federal de Minas Gerais, Belo Horizonte.

GOMES, C.M. Pesquisa cientifica em lazer no Brasil: bases documentais e teóricas. 2004. 2v. Dissertação (Mestrado em Ciências da Comunicação) - Universidade de São Paulo, São Paulo.

GOMES, C.M.; REJOWSKI, M. Lazer enquanto objeto de estudo científico: teses defendidas no Brasil. Licere, Belo Horizonte, v. 8, n. 2, p. 9-28, 2005.

GOMES TUBINO, M.J. Colônia de férias. Revista Brasileira de Educação Física, Rio de Janeiro, v. 12, p. 54-61, 1973.

GOUVÊA, R.; CAMPOS, M.E.R.; CUNHA, M.A. Jogos infantis. São Paulo: Nacional; Brasília, DF: Departamento de Educação do Distrito Federal, 1934.

GOUVÊA, R. Os jogos dirigidos na educação integral. Revista de Ensino, Belo Horizonte, v. 17, n. 193, p. 177-84, jul./dez. 1949.

GUIMARÃES, A.V. Abordagens do lazer e suas inter-relaçôes com o trabalho e a tecnologia na produção acadêmica brasileira na área do lazer. 2001. Dissertação (Mestrado) - Centro Federal de Educação Tecnológica de Minas Gerais, Belo Horizonte.

KISHIMOTO, T.M. Jogos tradicionais infantis: o jogo, a criança e a educação. Petrópolis: Vozes, 1993.

LAFARGUE, P. O direito à preguiça. São Paulo: Kairós, 1980.

LINSON, E.D. O lazer é um problema nos países em desenvolvimento? Documento, Rio de Janeiro, n. 96, 1975. 
Levantamento do estado da arte nos estudos do lazer: (Brasil) séculos XX e XXI...

MARCASSA, L. A invenção do lazer: educação, cultura e tempo livre na cidade de São Paulo (1888-1935). 2002. 204f. Dissertação (Mestrado) - Faculdade de Educação, Universidade Federal de Goiás, Goiânia.

MARCELlinO, N.C. Lazer e humanização. Campinas: Papirus, 1983.

MARCELLINO, N.C. Interesses físicos no lazer: o querer e o fazer algumas observações preliminares. Revista Brasileira de Ciências do Esporte, São Caetano do Sul, v. 4, p. 86-88, 1990.

MARCELlinO, N.C. Lazer e educação. Campinas: Papirus, 1990.

MARCELLINO, N.C. (Org.). Lazer: formação e atuação profissional. Campinas: Papirus, 1995.

MARCELlinO, N.C. (Org.). Políticas públicas setoriais de lazer: o papel das prefeituras. Campinas: Autores Associados, 1996.

MARCELLINO, N.C. (Org.). Lazer e empresa. Campinas: Papirus, 1999.

MARCELLINO, N.C. (Org.). Lúdico, educação e educação física. Ijuí: UNIJUÍ, 1999.

MARCUSE, H. Ideologia da sociedade industrial. Rio de Janeiro: Zahar, 1967.

MARCUSE, H. Eros e civilização. Rio de Janeiro: Zahar, 1968.

MARINHO, I.P. Educação física, recreação e jogos. São Paulo: Nacional, 1971.

MARINHO, I.P. Raízes etimológica, histórica e juridica do lazer. Brasília, DF: Empresa Gráfica e Jornalística Horizonte, 1979.

MASCARENHAS, F. Entre o ócio e o negócio: teses acerca da anatomia do lazer. 2005. 307f. Tese (Doutorado) - Faculdade de Educação Física, Universidade Estadual de Campinas, Campinas.

MEDEIROS, E.B. Reminiscências de uma educadora: mais de meio século de trabalho em recreação e lazer. In: SEMINÁRIO "O LAZER EM DEBATE”, 4., 2003, Belo Horizonte. Coletânea... Belo Horizonte: UFMG, 2003.

MEDEIROS, E.B. O lazer no planejamento urbano. 2. ed. Rio de Janeiro: FGV, 1971. 
MEDEIROS, E.B. Atividades lúdicas populares. In: Ferreira, A.B.H. Grande dicionário brasileiro da língua portuguesa. Rio de Janeiro: Delta, 1971. (Verbete).

MEDEIROS, E.B. O educador e a atividade criadora. Boletim Bibliográfico do SESC, Rio de Janeiro, n. 8, p. 79-88, dez. 1972.

MEDEIROS, E.B. O lazer no mundo atual. Boletim do CELAR, Porto Alegre, v. 1, n. 3, p. 26-28, maio 1974.

MEDEIROS, E.B. Valor da recreação nos países em desenvolvimento. Revista de Educação Física, Rio de Janeiro, v. 4, n. 11, p. 13-15, 1974.

MEDEIROS, E.B. Lazer: necessidade ou novidade? Rio de Janeiro: SESC/ADRJ, 1975

MELO, V.A. A animação cultural no Brasil: um panorama. Foro Permanente de Tiempo Libre y Recreacion. Disponível em: <http:// ar.geocities.com/foropermanetedetiempolibre/victor.htm $>$. Acesso em: 11 set. 2005.

MILLS, C.W. A nova classe média. Rio de Janeiro: Zahar, 1969.

MIRANDA, N. O significado de um parque infantil em Santo Amaro. São Paulo: Tipografia das Flores, 1938.

MIRANDA, N. Clubes de menores operários. Revista do Arquivo Municipal, São Paulo, n. 68, 1938.

MIRANDA, N. Recreação para a criança santista. São Paulo: Departamento de Cultura, 1938.

OLIVEIRA, P.S. Veblen e a sociologia do lazer. In: ENCONTRO NACIONAL DE HISTORIA DO ESPORTE, LAZER E EDUCAÇÃO FÍSICA, 3., 1995, Curitiba. Coletânea... Curitiba: CNPq, 1995. p. 23-28.

OLIVEIRA, P.S. O tempo e a máquina: um debate entre Karl Marx e Paul Lafargue. In: SEMINÁRIO “O LAZER EM DEBATE”. Coletânea... Belo Horizonte: UFMG, 2002. v. 1, p. 36-42.

OTÃO, J. A educação permanente e o lazer. Revista Brasileira de Cultura, Rio de Janeiro, v. 5, n. 18, p. 67-76, out./dez. 1973. 
Levantamento do estado da arte nos estudos do lazer: (Brasil) séculos XX e XXI...

PADILHA, V. Tempo livre e capitalismo: um par imperfeito. Campinas: Alínea, 2000.

PADILHA, V. Shopping center: a catedral das mercadorias. São Paulo: Boitempo, 2006.

PARENTE, J.I. Lazer e psicologia preventiva. In: ENCONTRO NACIONAL SOBRE LAZER, 1., 1977, Rio de Janeiro. Anais... Belo Horizonte: SESC, 1977. p. 56-62.

PARENTE FILHO, J.I.S. Lazer e psicologia preventiva. Cadernos de Lazer, São Paulo, n. 3, p. 51-60, 1978.

PEIXOTO, E. O jogo dos sentidos no discurso da teoria do lazer e em sua difusão. In: Peixoto, E. Para não deixar o cérebro na máquina. 1996. Dissertação (Mestrado) - Faculdade de Educação Física, Universidade Estadual de Campinas, Campinas.

PEIXOTO, E. Para não deixar o cérebro na máquina: o jogo dos sentidos no processo de produção do discurso do lazer. Motrivivência, Florianópolis, v. 8, n. 9, p. 246-256, dez. 1996.

PICHELI, V. O IDORT enquanto proposta educacional no contexto de formação da hegemonia burguesa no Brasil 1930-1945. 1997. Dissertação (Mestrado) - Faculdade de Educação, Universidade Estadual de Campinas, Campinas.

PIMENTEL, G.G.A. De jogo caipira a esporte country: novas configuraçōes culturais do rodeio no Brasil. In: CONGRESSO MUNDIAL DO LAZER, wrla, 5., 1998, São Paulo. Anais... São Paulo: SESC, 1998.

PITHAN E SILVA, N. Recreação: jogos, diversões, passatempos. 2 ed. São Paulo: Companhia Brasil, 1971.

REALE, M. O direito de não trabalhar. In: Reale, M. Tendências do direito do trabalho contemporâneo. São Paulo: LTR, 1980. p. 115-120.

REQUIXA, R. As dimensões do lazer. São Paulo: SESI, 1969

REQUIXA, R. Lazer e ação comunitária. São Paulo: SESC, 1973

REQUIXA, R. As dimensões do lazer. São Paulo: SESC, 1974

REQUIXA, R. O lazer e a civilização urbana. Cadernos de Lazer, São Paulo, n. 1, p. 43-75, jul. 1976. 
REQUIXA, R. O lazer na grande cidade e os espaços urbanizados. Cadernos de Lazer, São Paulo, v. 1, n. 1, p. 17-36, 1977.

REQUIXA, R. O lazer no Brasil. São Paulo: SESC, 1977.

REQUIXA, R. Sugestóes de diretrizes para uma politica nacional de lazer. São Paulo: SESC, 1980.

REQUIXA, R. El centro de estudios del ocio (espanhol e inglês). In: CONGRESSO MUNDIAL DE SOCIOLOGIA, 10., 1982, México. Anais... São Paulo: SESC, 1982

RIOPARDENSE, F.M. O uso do tempo e o equipamento urbano de recreação. Porto Alegre: UfRGS, 1970.

RUSSELL, B. O elogio do lazer. São Paulo: Nacional, 1957.

SÁ, K.O. Lazer, trabalho e educação: pressupostos ontológicos dos estudos do lazer no Brasil. 2002. Dissertação (Mestrado) - Faculdade de Educação, Universidade Federal da Bahia, Salvador.

SÁ, K.O. Pressupostos ontológicos dos estudos do lazer no Brasil. In: Chaves, M.; Gamboa, S.S.; SÁ, K.O. Lazer e recreação no currículo de educação física. Maceió: EDUFAL, 2003. p. 155-197.

SAVIANI, D. Escola e democracia - I: a teoria da curvatura da vara. In: Saviani, D. Escola e democracia. São Paulo: Autores Associados, 1983. p. 40-61.

SILVA, M.R. Trama doce-amarga: exploração do trabalho infantil e cultura lúdica. São Paulo: Hucitec, 2003.

SILVA, R.V.S.; ALVES, M.B.M.; PRINGOLATO, E.M.P. (Org.). Produção científica em educação física e esportes: dissertações e teses 1979-1994. Uberlândia: Ufu/NUBRADITEFE, 1996.

SODRÉ, F. As necessidades dos operários brasileiros. Revista de Estudos Brasileiros, Rio de Janeiro, v. 1, n. 1, p. 66-82, jul./ago. 1938.

STRAMANDINOLI, C.T. Aspectos psicológicos do lazer. Boletim do Centro de Estudos da Maternidade Carmelo Dutra, Rio de Janeiro, v. 4, n. 6, p. 59-72, 1971. 
Levantamento do estado da arte nos estudos do lazer: (Brasil) séculos XX e XXI...

SUSSEKIND, A. Trabalho e recreação: fundamentos, organização e realizaçōes da S.R.o. Rio de Janeiro: Ministério do Trabalho, Indústria e Comércio, 1946.

SUSSEKIND, A. Recreação operária. Rio de Janeiro: Ministério do Trabalho, Indústria e Comércio, 1948.

SUSSEKIND, A. Duração do trabalho e repousos remunerados. Rio de Janeiro: Freitas Bastos, 1950.

SUSSEKIND, A. Convençōes da OIT. São Paulo: LTR, 1994.

SUSSEKIND, A. A chave do sucesso: Arnaldo Sussekind - um cidadão ilustre. Revista Prática Jurídica, Brasília, DF, v. 3, n. 30, p. 6-9, set. 2004.

SUSSEKIND, A.; MARINHO, I.P.; GÓES, O. Manual de recreação: orientação dos lazeres do trabalhador. Rio de Janeiro: Ministério do Trabalho, Indústria e Comércio, 1952.

VALENTE, M.C. Recreação e lazer: o conhecimento teórico disponível em livros, teses e dissertações. In: Lazer e recreação no currículo de educação fisica. Maceió: EDUFAL, 1997. p. 21-52.

VEBLEN, T. A teoria da classe ociosa. São Paulo: Pioneira, 1965.

WERNECK, C.L.G.; STOPPA, E.; ISAYAMA, H.F. (Org.). Lazer e mercado. Campinas: Papirus, 2001.

WERNECK, C.L.G.; ISAYAMA, H.F. (Org.). Lazer, recreação e educação física. Belo Horizonte: Autêntica, 2003.

YURGEL, M. Encontro de Varna: um congresso da UIA sobre o lazer. In: A construção em São Paulo, São Paulo, p. 8-9, 26 jun. 1972.

YURGEL, M. Para uma arquitetura do lazer. Revista de Cultura Vozes, Petrópolis, v. 3, p. 61-64, 1973.

YURGEL, M. Triste tempo livre. Revista Visão, São Paulo, 16 dez. 1974. 